- Supporting Information -

\title{
Sources of oxygen produced in the chlorate process utilizing DSA electrodes doped by Sn and Sb
}

Aleksandra Lindberg ${ }^{a}$, Oscar Diaz-Morales ${ }^{a}$, Susanne Holmin ${ }^{b}$ and Ann Cornell ${ }^{a}$

\footnotetext{
${ }^{a}$ Applied Electrochemistry, School of Engineering Sciences in Chemistry, Biotechnology and Health, KTH Royal Institute of Technology, SE 10044 Stockholm, Sweden

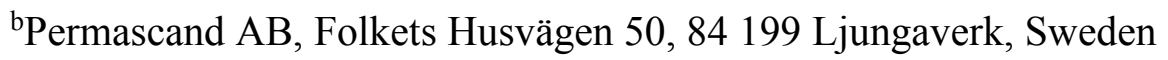


Electrode preparation

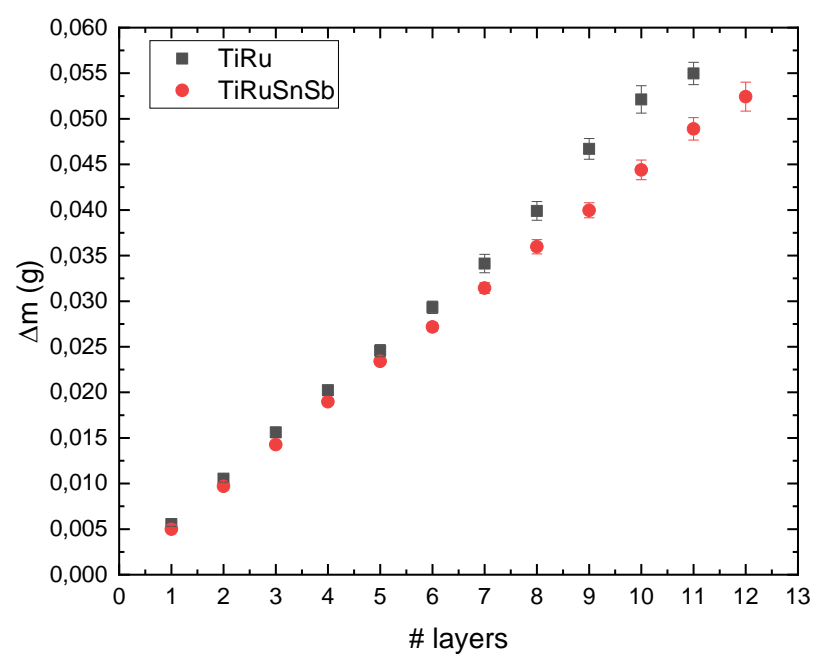

Figure S1. Layer growth with number of coating sequences by brush coating $50 \mu 1$ of precursor solution, drying on $80^{\circ} \mathrm{C}$ for $10 \mathrm{~min}$ and annealed on $470^{\circ} \mathrm{C}$ for $10 \mathrm{~min}$

Electrode characterization

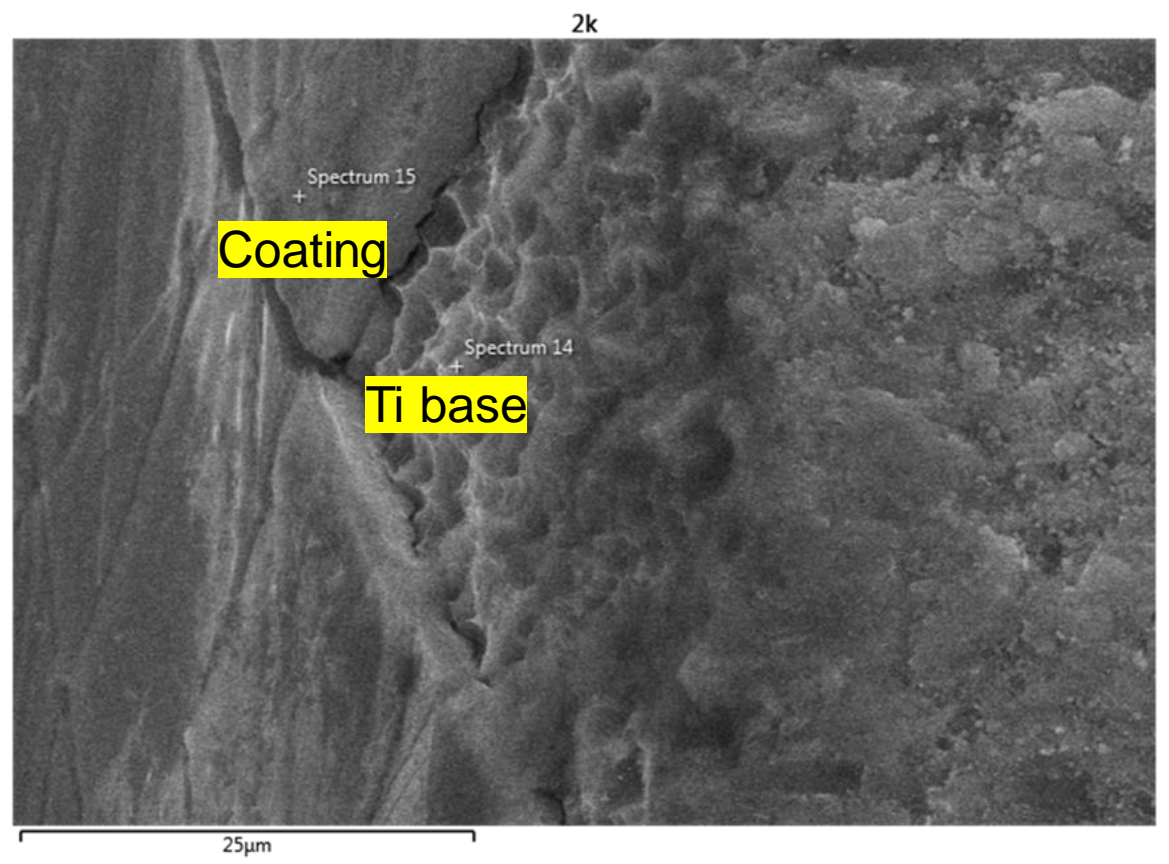

Figure S2. SEM image of cross section of TiRuSnSb electrode 
A)

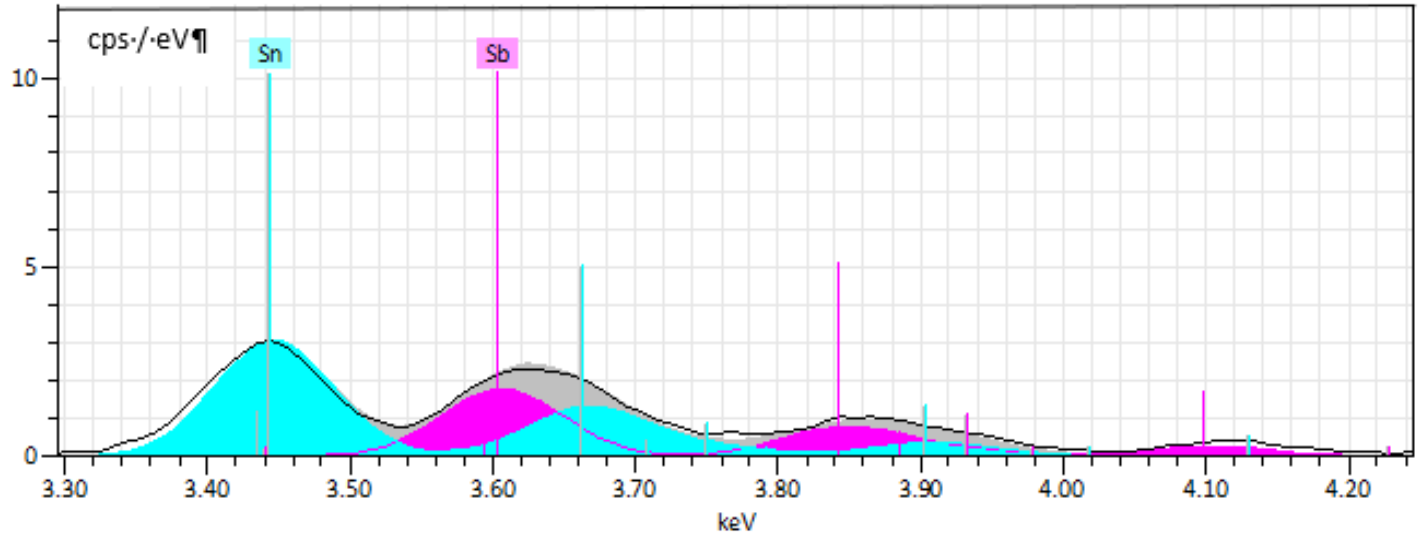

B)

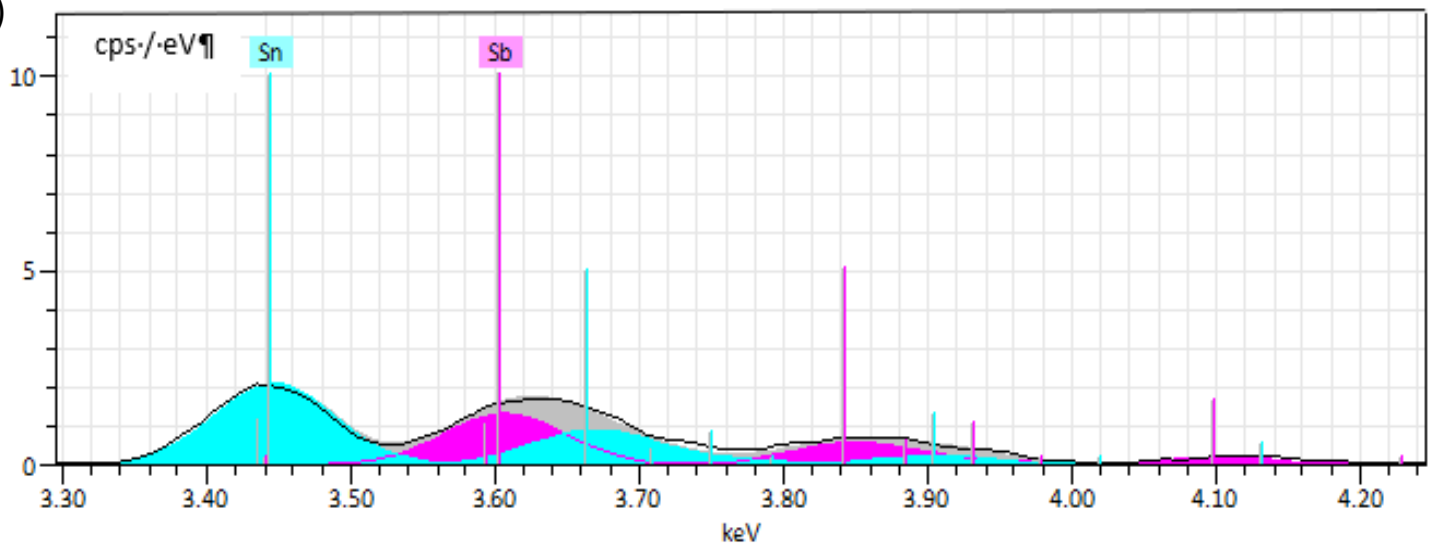

Figure S3. EDX spectra with deconvoluted peaks for Sb and Sn: A) TiRuSnSb_1 (fresh electrode), B) TiRuSnSb_2 (reused electrode)

Table S1. SEM-EDX results taking into account only metal content

\begin{tabular}{|c|c|c|c|c|c|c|}
\hline at & $\begin{array}{l}\text { TiRu - } \\
\text { fresh }\end{array}$ & $\begin{array}{l}\mathrm{TiRu}- \\
\text { used }\end{array}$ & $\begin{array}{l}\mathrm{TiRu}- \\
\text { expected }\end{array}$ & $\begin{array}{l}\text { TiRuSnSb - } \\
\text { fresh }\end{array}$ & $\begin{array}{l}\text { TiRuSnSb- } \\
\text { used }\end{array}$ & $\begin{array}{l}\text { TiRuSnSb - } \\
\text { expected }\end{array}$ \\
\hline $\mathrm{Ti}$ & 80.0 & 81.2 & 70 & 65.3 & 67.6 & 34 \\
\hline $\mathrm{Ru}$ & 20.0 & 18.8 & 30 & 25.6 & 25.6 & 30 \\
\hline $\mathrm{Sn}$ & I & I & & 5.8 & 3.9 & 30 \\
\hline $\mathrm{Sb}$ & I & I & & 3.3 & 2.9 & 6 \\
\hline
\end{tabular}


Electrochemical measurements

Table S2. Voltammetric charge for TiRu and TiRuSnSb electrode

\begin{tabular}{c|c|c} 
& TiRu & TiRuSnSb \\
\hline $\mathrm{q} * / \mathrm{C} \mathrm{cm}^{-2}$ & 0.02616 & 0.04555
\end{tabular}

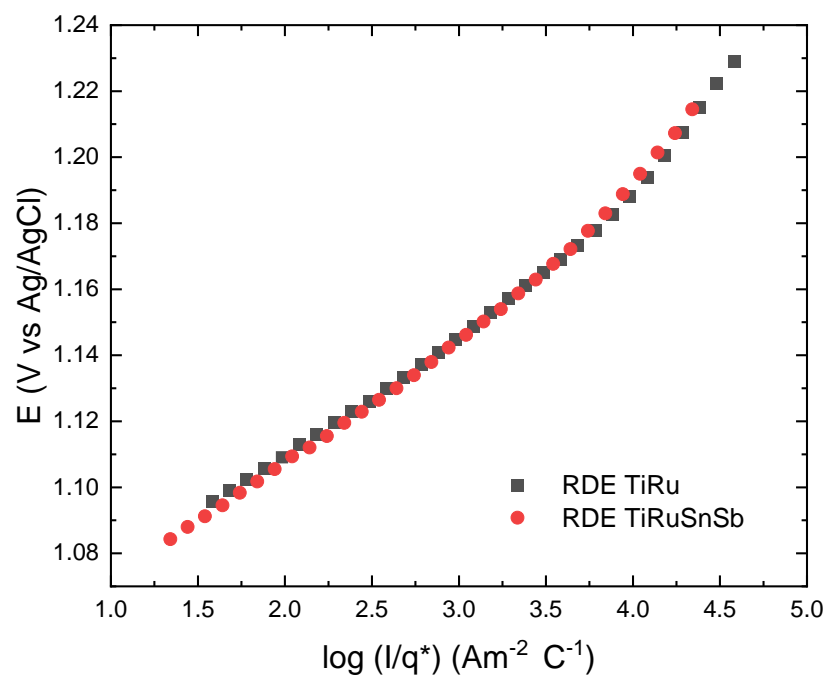

Figure S4. Polarization curves of TiRu and $\mathrm{TiRuSnSb}$ electrodes recorded in $5 \mathrm{M} \mathrm{NaCl}$ solution, $\mathrm{pH}=2,22^{\circ} \mathrm{C}, 3000 \mathrm{rpm}$, normalized by the real surface area 
Difference RDE vs Flag

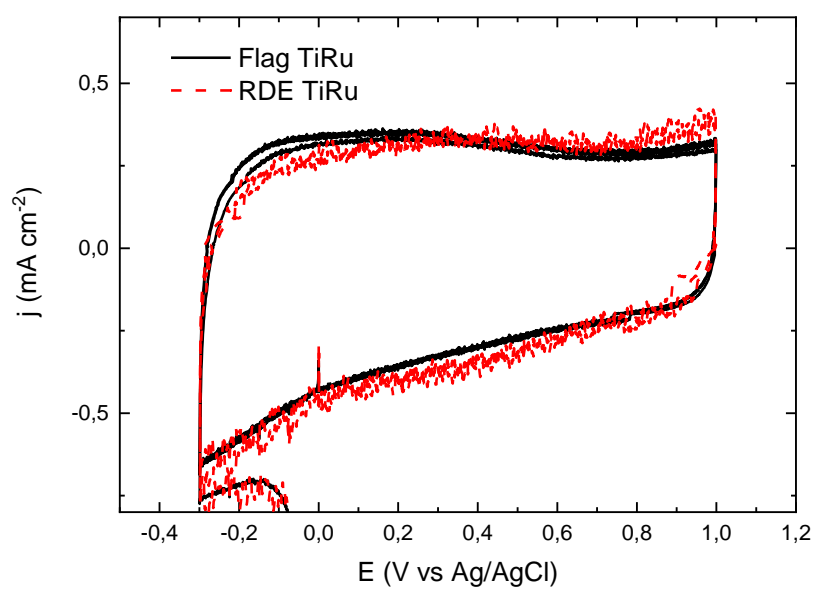

Figure S5. $\mathrm{CV}$ obtained in $5 \mathrm{M} \mathrm{NaCl}, \mathrm{pH}=2$ on $22^{\circ} \mathrm{C}$ with constant nitrogen purging for flag and rotating disc TiRu electrode, a scan rate $v=50 \mathrm{mV} \mathrm{s}^{-1}$, rotation speed $3000 \mathrm{rpm}$ for RDE

Electrochemical mass spectrometry measurement

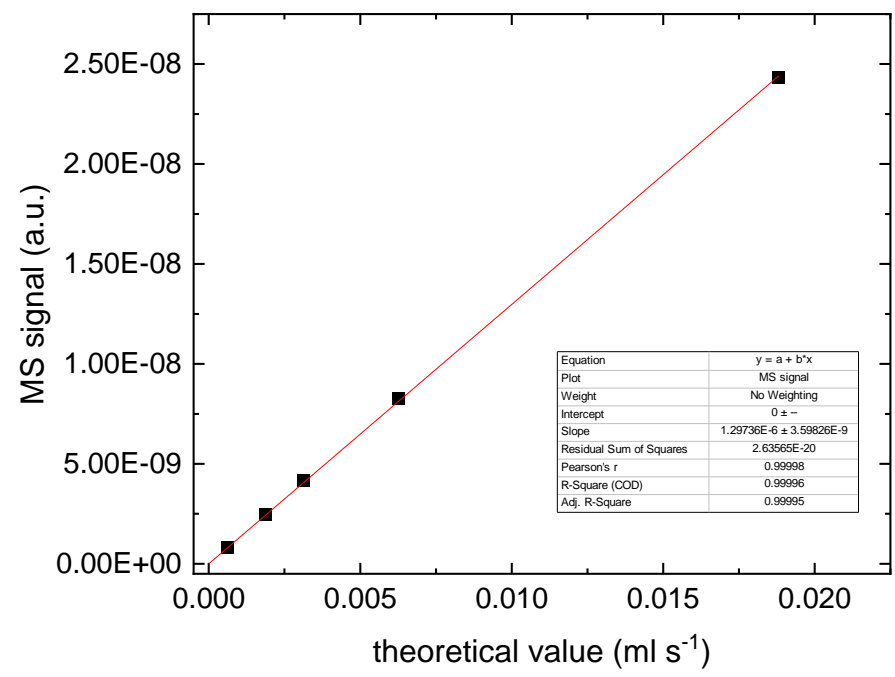

Figure S4. Mass spectrometer calibration curve obtained by galvanostatic measurements on different current levels in $1 \mathrm{M} \mathrm{NaOH}$ with two Pt electrodes 


\section{Non-electrochemically produced oxygen}
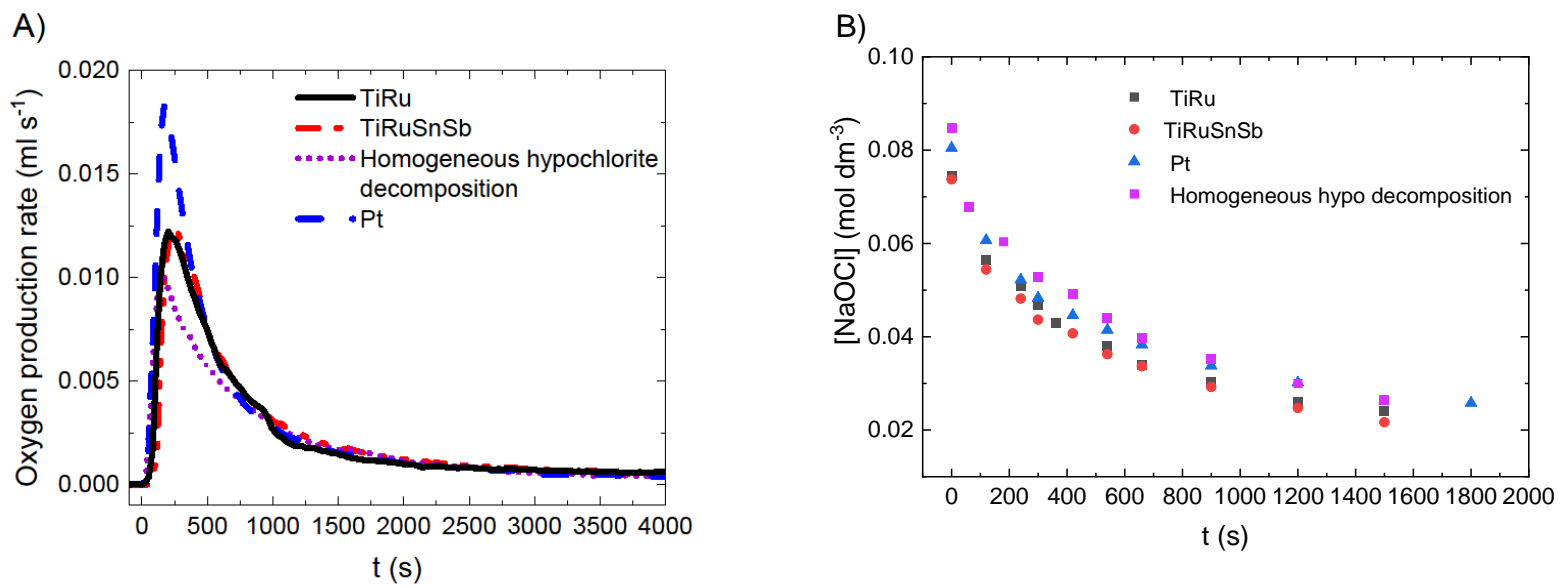

Figure S7. A) Heterogeneously formed oxygen in a $2 \mathrm{M} \mathrm{NaCl}+80 \mathrm{mM} \mathrm{NaOCl}$ (initial), at $80{ }^{\circ} \mathrm{C}$ and $\mathrm{pH}=6.5, \mathrm{~B}) \mathrm{Hypochlorite}$ species concentration

Rate constant of hypochlorite decomposition is calculated by applying following equations. Assuming the decomposition to be of first order in $\mathrm{ClO}^{-}$and second order in $\mathrm{HOCl}$.

$$
r=-k[\mathrm{HOCl}]^{2}\left[\mathrm{OCl}^{-}\right]
$$

Inserting

$$
C_{H}=[\mathrm{HOCl}]+\left[\mathrm{OCl}^{-}\right]
$$

and

$$
C_{H}=[H O C l]\left(1+10^{\left(p H-p K_{a}\right)}\right)
$$

will lead to:

$$
\frac{d C_{H}}{d t}=-k m C_{H}^{3} \text { where } m=\frac{10^{\left(p H-p K_{a}\right)}}{\left(1+10^{\left(p H-p K_{a}\right)}\right)^{3}}
$$

Integration of this expression gives:

$$
C_{H}^{-2}=2 k m t+C_{H, 0}^{-2}
$$

where $C_{H}$ is total hypochlorite concentration. 


\section{Electrochemically produced oxygen}

A)

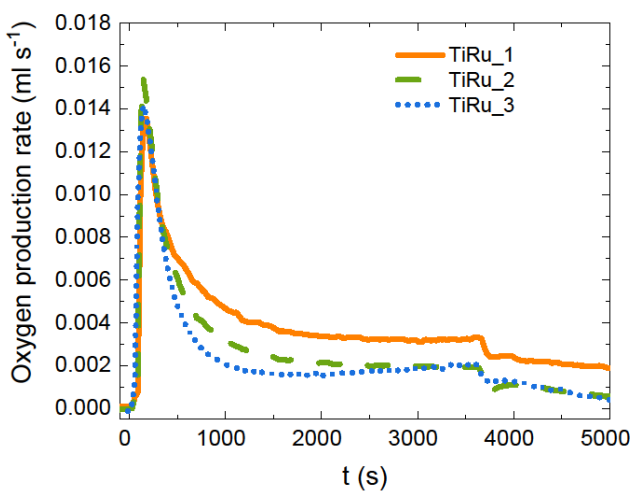

C)

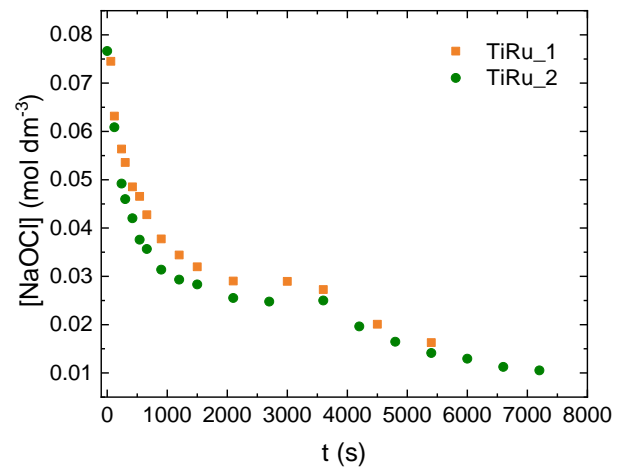

B)

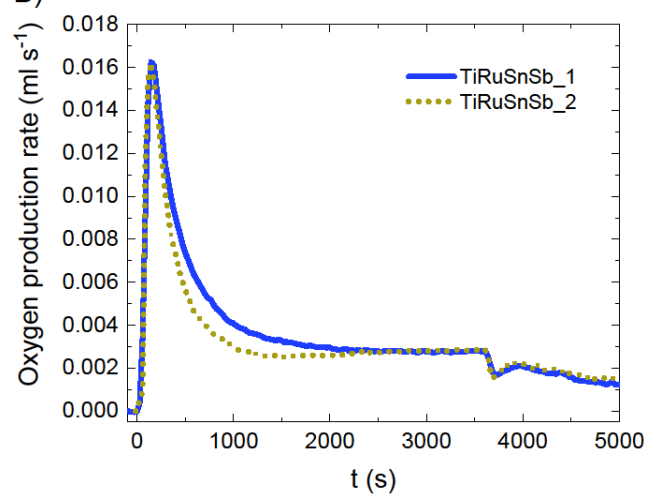

D)

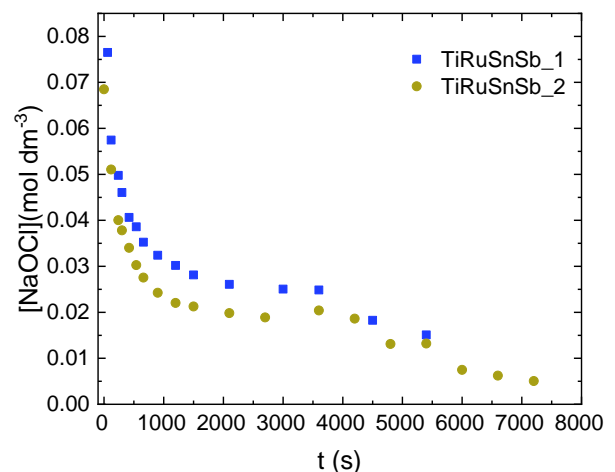

Figure S8 A) Oxygen production rate formed during the electrolysis of a $2 \mathrm{M} \mathrm{NaCl}+80 \mathrm{mM} \mathrm{NaOCl}$ (initial), at $80^{\circ} \mathrm{C}$ and $\mathrm{pH}=6.5$, using $300 \mathrm{~mA} \mathrm{~cm}^{-2}$ for $3600 \mathrm{~s}$, using TiRu electrodes: TiRu_1 (fresh) electrode and TiRu_2 (reused) electrode, B) Oxygen production rate formed during the electrolysis of a $2 \mathrm{M} \mathrm{NaCl}+80 \mathrm{mM} \mathrm{NaOCl}$ (initial), at $80^{\circ} \mathrm{C}$ and $\mathrm{pH}=6.5$, using $300 \mathrm{~mA} \mathrm{~cm}^{-2}$ for $3600 \mathrm{~s}$ : TiRuSnSb electrodes: TiRuSnSb_1 (fresh) electrode and TiRuSnSb_2 (reused) electrode, C) Hypochlorite species concentration in case of electrolysis using TiRu electrodes, D) Hypochlorite species concentration in case of electrolysis using TiRuSnSb electrodes

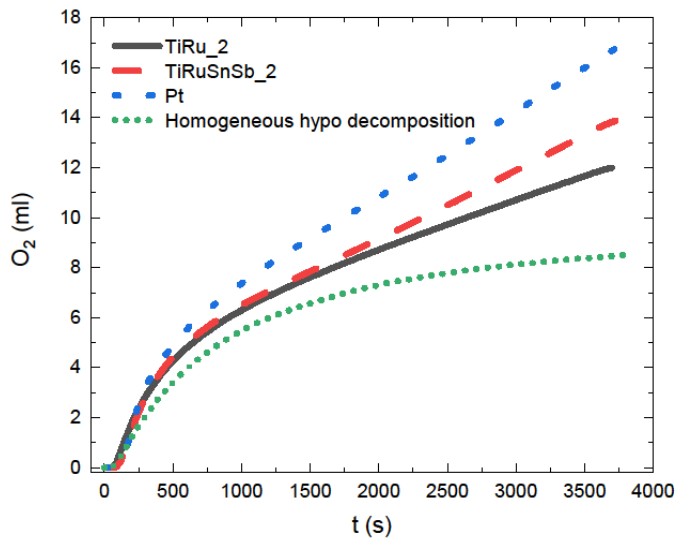

Figure S9. Oxygen formed during the electrolysis of a $2 \mathrm{M} \mathrm{NaCl}+80 \mathrm{mM} \mathrm{NaOCl}$ (initial), at $80{ }^{\circ} \mathrm{C}$ and $\mathrm{pH}=6.5$, using $300 \mathrm{~mA} \mathrm{~cm}^{-2}$ for $3600 \mathrm{~s}$ 


\section{Different sources of oxygen}

TiRu

A)

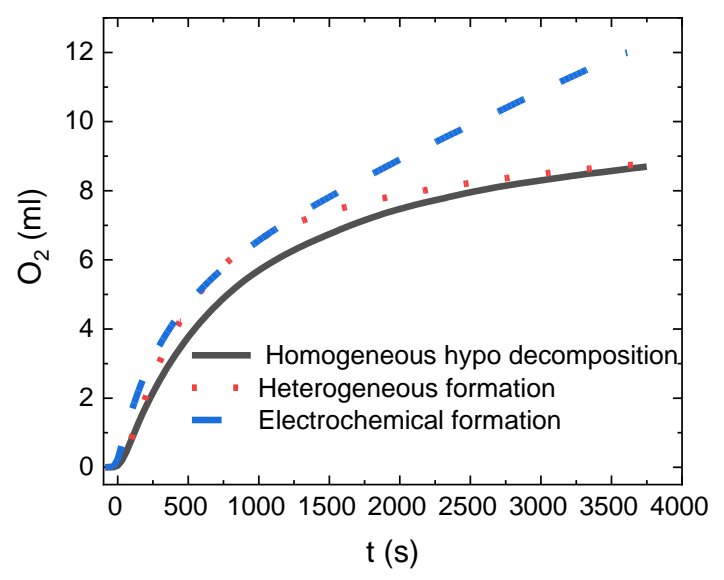

C)

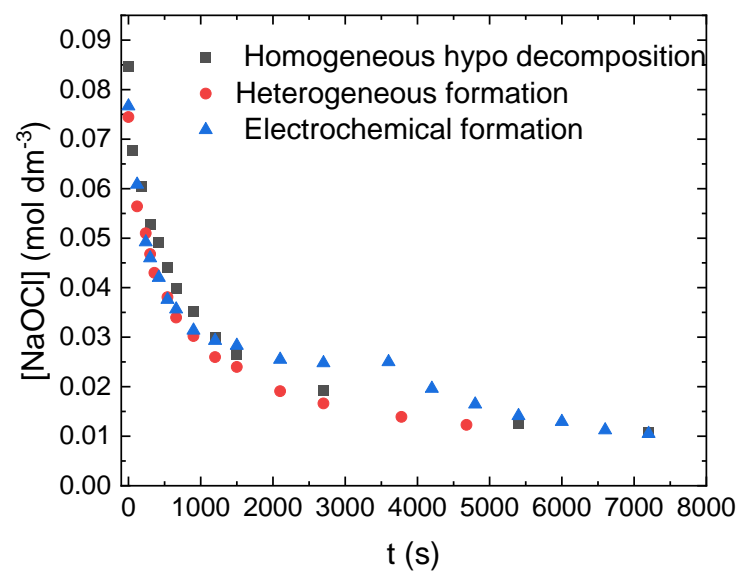

TiRuSnSb

B)

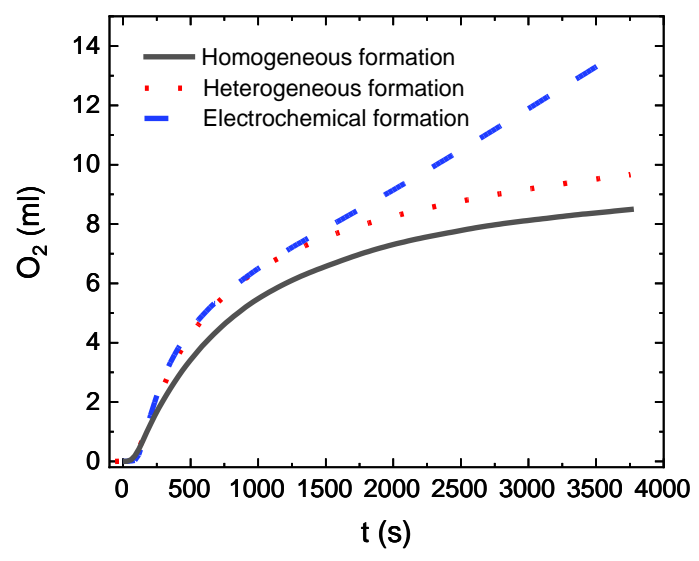

D)

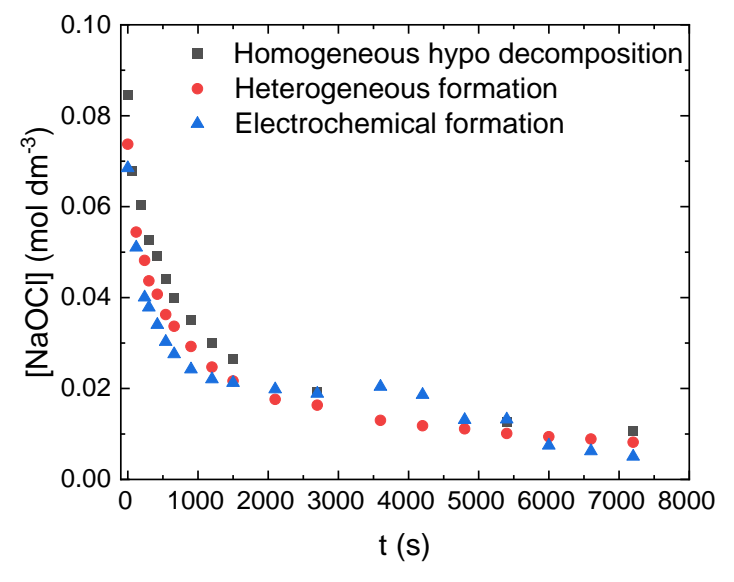

Figure S10. Oxygen volume formed in a $2 \mathrm{M} \mathrm{NaCl}+80 \mathrm{mM} \mathrm{NaOCl}$ (initial), at $80{ }^{\circ} \mathrm{C}$ and $\mathrm{pH}=6.5$, for 3 cases: homogeneous hypochlorite decomposition, heterogeneous formation during electrodes present in the solution (without current) and electrolysis ( $300 \mathrm{~mA} \mathrm{~cm} \mathrm{~cm}^{-2}$ for $3600 \mathrm{~s}$ ) using: A) TiRu electrodes, B) TiRuSnSb electrodes. Hypochlorite species concentration in case of homogeneous hypochlorite decomposition, heterogeneous formation of oxygen, and electrochemically produced oxygen by electrolysis using: C) TiRu electrodes, D) TiRuSnSb electrodes 